\title{
Chebyshev Approximation for Nanofluid flow of Non-Isothermal Channel Flow under Constant Heat Flux
}

\author{
Coşkun ÖZALP*1, Betül TEYMUR ${ }^{1}$, Bülent YANIKTEPE ${ }^{1}$, Muharrem IMAL $^{2}$ \\ ${ }^{1}$ Osmaniye Korkut Ata University, Energy Systems Engineering, Osmaniye, Turkey \\ ${ }^{2}$ Kahramanmaras S.I. University, Mechanical Engineering, Kahramanmaras, Turkey
}

\begin{abstract}
This paper investigates the Nano-fluid for a non-isothermal channel flow under the effect of a constant pressure gradient acting along the channel axis. Two-dimensional, non-isothermal, steady flow of an incompressible fluid in a channel is taken into consideration. Upper and lower walls of the channel are kept at the same constant heat flux. To consider the effect of conductivity and viscosity, Maxwell and Brinkman's models are used respectively. The effects of volume fraction, pressure gradient and Reynolds numbers on velocity and temperature profiles are discussed for the Nano-fluid Alumina. Water is used as a base fluid. The comparisons of the flow characteristics, including the distributions of velocity, temperature and volumetric flow rate of aluminum oxide are also given in the paper. Shear stress distribution along the channel axis and pressure gradient for different volume fraction are presented as well. Discretization is performed using a Pseudospectral technique based on Chebyshev polynomial expansions. The resulting nonlinear, coupled boundary value problem is solved iteratively using Chebyshev pseudospectral method.
\end{abstract}

Keywords: Nano-Fluid, Non isothermal channel flow, Pseudospectral technique

\section{Sabit Isı Akısı Altında İzotermal Olmayan Kanal Akışında Nanoakışlar İçin Chebyshev Yaklaşımı}

ÖZET: Bu çalışmada sabit basınç gradyanının etkisi altındaki nanoakışkanın izotermal olmayan kanaldaki akışı sayısal olarak incelenmiştir. Kanal akışının çözümünde akışın iki boyutlu, izotermal olmayan, sıkıştırılamaz, hidrodinamik ve ısıl olarak tam gelişmiş ve sürekli olduğu kabul edilmiştir. Kanal alt ve üst cidarlarına sabit 1sı akısı sınır şartı uygulanmış olup alümina-su nanoakışkanın tek fazlı ve homojen olduğu varsayılmıștır. Momentum ve enerji denklemlerinde yer alan 1 sıl iletkenlik ve viskozite değerleri için hacimsel konsantrasyona bağlı olarak sırasıyla Maxwell ve Brinkman modelleri kullanılmıştır. Kanal içindeki alümina-su nanoakışkanın hacimsel konsantrasyon, basınç gradyanı ve Reynolds sayısının sıcaklık ve hız profiline etkisi incelenmiştir. Su temel akışkan olarak ele alınmıștır. Ayrıca kanal merkezi boyunca kayma gerilmesi dağılımı ve farklı hacimsel debilerdeki basınç gradyanı değişimi de incelenmiştir. Denklemlerin ayrıklaştırılması Chebyshev polinom açılımlarına dayanan Pseudospectral yöntemi kullanılarak yapılmış ve doğrusal olmayan sınır değer problemleri Chebyshev Pseudospectral yöntemi ile sayısal olarak çözülmüşsür.

Anahtar Kelimeler: Nanoakışkan, İzotermal Olmayan Kanal Aklşıl, Pseudospectral yöntemi

\section{INTRODUCTION}

Due to enhanced thermal conductivity and heat transfer performance compared to the base fluids, Nanofluids are used in many thermal applications and industries. Despite so many papers published in the fields of Nano-fluids, this research area is still openended. Maxwell (1904) published historical and pioneer study about a hundred years ago. After that numerous theoretical (see in particular, Jeffrey, 1973; Batchelor, 1977; Gupte et al., 1995) and experimental studies (see for example, Boothroyd and Haque, 1970; Sohn and Chen, 1981; Kurosaki and Murasaki, 1986) were published. They conducted on liquids and gas containing suspended solid particles. Sohn and Chen, (1981) and Ahuja, (1982) working on the liquid-solid particle mixtures observed that heat transfer of the liquid-solid particle mixtures increased. Due to the increase in the thermal effective conductivity, such enhancement is realized. On the other side, it was considered that because of the presence of particles and their random motion within the base fluid, such heat transfer enhancement may have important contributions to the target area as well. However, it should be noted that these studies were concerned with mixtures containing millimeter or micrometer size particles that, unfortunately, introduced serious drawbacks such as drastic pressure drop, rapid settling of particles, severe

\footnotetext{
*Sorumlu Yazar: Coskun OZALP coskunozalp@osmaniye.edu.tr
} 
clogging as well as premature wear of flow channels and its components. All of these difficulties restrained practical application of such mixtures, but in recent years, modern technologies have made possible for fluid production which is called nanoparticles.

Since the solid nanoparticles with typical length scale of 1-100 nm with high thermal conductivity are suspended in the base fluids having low thermal conductivity, nano particles have been shown to enhance effective thermal conductivity and convective heat transfer coefficient of the base fluid. The thermal conductivity of the particle materials, metallic or nonmetallic such as $\mathrm{Al}_{2} \mathrm{O}_{3}, \mathrm{CuO}, \mathrm{Cu}, \mathrm{SiO}_{2}, \mathrm{TiO}_{2}$, are typically order-of-magnitude higher than the base fluids even at low concentrations, resulting in significant increases in the heat transfer coefficient. Therefore, the effective thermal conductivity of nano-fluids is expected to enhance heat transfer compared with conventional heat transfer liquids.

In fact, several researches, see in particular, (Masuda et al., 1993; Choi, 1995; Lee et al., 1999) showed that with low nanoparticles concentrations (1-5 Vol\%), the thermal conductivity of the suspensions can increase more than $20 \%$. It is important to note that such an increase in the thermal conductivity of nano-fluids depends mainly on the thermal conductivity of solid particles and base fluid, particle volume fraction, shape and size of particles. Over a decade ago, researchers focused on measuring and modeling the effective thermal conductivity and viscosity of nano-fluids. An important review of experimental works on the effective thermal conductivity of nano-fluids and heat transfer enhancement is given by $\mathrm{Yu}$ et al, 2007.

Lee et al. (1999) investigated experimentally the thermal conductivity behavior of oxide Nano-fluids with low particle concentrations (1-5 vol.\%). They measured the thermal conductivity of four oxide Nanofluids $\left(\mathrm{A}_{2} \mathrm{O}_{3}\right.$ in water, $\mathrm{A}_{2} \mathrm{O}_{3}$ in ethylene glycol, $\mathrm{CuO}$ in water, and $\mathrm{CuO}$ in ethylene glycol) by a transient hotwire method, and found that the thermal conductivity enhancement increases linearly with increasing particle volume concentration by more than $\% 20$ at $4 \%$ volume fraction. Moreover, they concluded that the conductivity ratio increases of ethylene glycol nano-fluid systems are always higher than those of water nano-fluid systems for nano-fluids using the same nanoparticles; the conductivity ratio of the $\mathrm{CuO}$ system is always higher than that of the $\mathrm{A} 1_{2} \mathrm{O}_{3}$ system for nano-fluids using the same liquid.

Wang et al. (1999), Lee et al. (1999), Xie et al. (2002-a-b-c), and Das et al.(2003) investigated the effect of particle size of nanoparticles. They work on spherical particles for a single particle-water combination over a range of particle diameter from 20 $\mathrm{nm}$ to $60 \mathrm{~nm}$. General trend is that the thermal conductivity of nano-fluid increases with increasing particle diameter conductivity. Furthermore, some theories predict that heat transfer increases better when small particles disperse a uniform. The effect of particle shape on the thermal conductivity enhancement in Nano-fluid was investigated by Xie et al. (2002-a) and the experimental results were compared to the geometric shape of the particle with the same material and base fluid. It was obtained that thermal conductivity goes up by the use of elongated particles. They used 26 $\mathrm{nm}$ spherical and $600 \mathrm{~nm}$ cylindrical particles of $\mathrm{SiC}$ in ethylene glycol base fluid. It is found that at 3\% volume concentration, the thermal conductivity ratio of 1.16 and 1.10 was obtained for cylindrical and spherical particles respectively. The problem of laminar forced convection flow of nano-fluids was thoroughly investigated by Maiga et al. (2005), by numerical simulation. They studied straight heated tube and a radial space between coaxial and heated disks to obtain hydrodynamic and thermal characteristics of Nano-fluids for water- $\mathrm{Al}_{2} \mathrm{O}_{3}$ and Ethylene Glycol- $\mathrm{Al}_{2} \mathrm{O}_{3}$ mixtures. The results clearly revealed that such as the other studies found out the heat transfer coefficient increases remarkably with the addition of nanoparticles with respect to that of the base liquids and with an increase of the particle concentration. On the other hand, the presence of such particles has also induced drastic effects on the wall shear stress that increases respectable with the particle concentration. They revealed that among the mixtures studied, the heat transfer enhancement of Ethylene Glycol- $\mathrm{Al}_{2} \mathrm{O}_{3}$ Nano-fluid is better than water- $\mathrm{Al}_{2} \mathrm{O}_{3}$; it means more pronounced adverse effects on the wall shear stress. Furthermore, Maiga et al. investigated the impact of Reynolds number and said that heat transfer enhancement also increases with an augmentation of the flow Reynolds number for tube flow. On the other hand, for the case of a radial laminar flow, they found that both the Reynolds number and the gap between disks seem not to have significant effect on the heat transfer enhancement. Thermal conductivity, viscosity and heat transfer coefficient in pipe flow of water-based alumina and titania nano-fluids were investigated experimentally and theoretically by Utomo et.al (2012). They obtained concordant results between experimental results and correlations commonly used in literature review. They enounced that the thermal conductivity of alumina Nano-fluids follows the prediction of Maxwell model, whereas that of titania Nano-fluids is slightly lower than the model prediction due to higher additives concentration.

Shojaeian and Kosar (2014) investigated analytically convective heat transfer and entropy generation in Newtonian and non-Newtonian fluid flows between parallel-plates with velocity slip boundary condition for both isoflux and isothermal thermal boundary conditions by taking into consideration the effects of wall slip and viscous dissipation. The effects of key parameters such as slip 
coefficient, b, power-law index, $\mathrm{n}$, and Brinkman number, $\mathrm{Br}$, on Nusselt number, entropy generation rate and Bejan number were assessed. According to the results, these governing parameters influence drastically heat transfer characteristics of non-Newtonian micro flows. Furthermore, they put forward to the following results: the more either power-law index or Brinkman number increases, the more decrease happens in Nusselt number and Bejan number, but they increase with slip coefficient. On the other hand, both power-law index and Brinkman number increases, the more global entropy generation rate does, too.

Mohammeda et al. (2011) clarified numerous researches in their study. They summarized this study on two sections. First section is focused on studying the fluid flow and heat transfer behavior of different types of single-phase fluid flows over backward facing step (BFS) at different orientations and second section is concentrated on everything related to Nano-fluids; its preparation, properties, behavior, applications, and many others.

Hatami et al. (2013) applied two analytical approaches called Least Square Method (LSM) and Collocation Method (CM) to find the most accurate solution of the heat transfer of sodium alginate-titanium dioxide ( $\mathrm{SA}-\mathrm{TiO}_{2}$ ) non-Newtonian Nano-fluid flow in the porous area between two coaxial cylinders. Viscosity of the Nano-fluid was considered as a function of temperature according to Reynolds model. They investigated the influences of the some physical parameters such as Brownian motion and thermophoresis parameters on non-dimensional velocity and temperature profiles. They stated that the results of LSM are more accurate than CM and temperature increases in whole domain with increasing thermophoresis parameter.

Bianco et al. (2011) worked on steady state turbulent forced convection flow of water $/ \mathrm{Al}_{2} \mathrm{O}_{3} \mathrm{Nano}-$ fluid within a circular tube heated with uniform heat flux. This situation was investigated numerically through the agency of finite volume method. They took into account two different approaches: single and twophase models, with diameter of alumina nanoparticles equal to $38 \mathrm{~nm}$ and with spherical shape. A results obtained by the different models were compared by means of temperature, velocity distributions and Nusselt number profiles. They indicated such numerous researchers that increase in the Reynolds number and particle volume concentration induces heat transfer enhancement.

Tso et al. (2010) analyzed both hydro-dynamically and thermally fully developed laminar heat transfer of non-Newtonian fluids between fixed parallel plates kept at different constant heat fluxes. They solved analytically the energy equation, and in turn the Nusselt number, in terms of Brinkman number and power-law index. They took into account the effect of viscous dissipation of the flowing fluid in parallel plates. Tso et al. underlined that the effects of the viscous dissipation should not be neglected and should have essential importance in the heat transfer analysis. Besides, they indicated that power-law index of the flowing fluid induces heat transfer. Two-phase Eulerian model was implemented by Lotfi et al. (2010) to study forced convective of a Nano-fluid consisting of water- $\mathrm{Al}_{2} \mathrm{O}_{3}$ in horizontal tubes. In addition, for comparison Nanofluids, two other different approaches were also used, which are a single-phase model. Two-phase mixture model and effects of nanoparticles concentration on the thermal parameters were also investigated. Lotfi et al. (2010) who studied numerically concluded that mixture model formulations were more reliable than singlephase model and the rate of thermal enhancement decreased with the increase of nanoparticles volume concentration. Duangthongsuk and Wongwises (2009) reported the thermal conductivity and dynamic viscosity of $\mathrm{TiO}_{2}$ nanoparticles dispersed in water with various particle volume concentration of \% 0.2-2 vol and with temperature ranging from 15 to $35^{\circ} \mathrm{C}$. A transient hotwire apparatus was used in their study for measuring the thermal conductivity of Nano-fluids at different temperatures while the Bohlin rotational rheometer (Malvern Instrument) was used for measuring the viscosity of Nano-fluids. The experimental results showed that viscosity and thermal conductivity of Nano-fluid increases as the particle concentrations do. Furthermore, in contrast to the viscosity, thermal conductivity of Nano-fluids increased with increasing Nano-fluid temperatures. They pointed out that, this measured thermal conductivity and viscosity of Nanofluids are rather different than the existing correlations and the data reported by other researchers. Besides, they proposed new correlations for predicting the thermal conductivity and viscosity of $\mathrm{TiO}_{2}$-water Nano-fluids. Convective heat transfer and flow field in wavy channel with Nano-fluids were studied by Heidary and Kermani (2010). The control volume approach based on the SIMPLE Technique was used in the domain in order to solve the governing equations numerically. CuO-water Nano-fluid was used for simulation. The effects of the Reynolds number ( $R e$ ) ranging from $5 \leq \mathrm{Re} \leq 1500$, volume fraction, $\phi$, ranging from $0 \leq \phi \leq 20 \%$ and the wave amplitude, $\alpha$, ranging from $0 \leq \alpha \leq 0.3$ were investigated on the local and average Nusselt numbers and the skin friction coefficient. With this study, it was concluded that heat transfer in channels can enhance by addition of Nano-particles, and usage of wavy horizontal walls.

Mohammed et al. (2011) investigated numerically the effects of using various types of particle in base fluid water (aluminum oxide $\left(\mathrm{Al}_{2} \mathrm{O}_{3}\right)$, silicon dioxide $\left(\mathrm{SiO}_{2}\right)$, silver $(\mathrm{Ag})$, and titanium dioxide $\left(\mathrm{TiO}_{2}\right)$ with three different nanoparticle volume fractions $(2 \%, 5 \%$ 
and 10\%), Reynolds numbers on heat transfer and fluid flow characteristics in a square shaped micro channel heat exchanger (MCHE). They used the finite volume method for solving governing equations. The performance of the MCHE were examined with respect to temperature profile, heat transfer rate, heat transfer coefficient, pressure drop, wall shear stress, pumping power, effectiveness, and overall performance index. It is concluded that Nano-fluids can augment the thermal properties and performance of the heat exchanger despite the fact that they have a slight increase in pressure drop. The pumping power increases with increasing the Reynolds number, whereas increasing the Reynolds number causes the effectiveness to decrease. Heat transfer performance of the nanoparticles was compared with each other's and concluded that Aluminum oxide Nano-fluid has the highest heat transfer coefficient among all the Nano-fluids tested. Also, it was indicated that silver-water Nano-fluid has the lowest pressure drop. Mahbubul et al (2012) compiled and reviewed different characteristics of viscosity of Nano-fluids including Nano-fluid preparation methods, temperature, particle size and shape, and volume fraction effects. In this paper, the researchers denoted that according to existing experimental results viscosity of Nano-fluids increased with an increase of volume concentration while decreasing with the temperature increase. Moreover, it was indicated that particle size effects highly the viscosity of nanoparticles. Convective heat transfer analysis for a gaseous slip flow in micro channels was performed numerically by Sun et al. (2007) for constant wall temperature, constant wall heat flux, and linear variation of wall temperature boundary conditions. The three boundary conditions were investigated by the finite-volume finite difference scheme with slip flow and temperature jump conditions. Besides, they presented the effects of Knudsen and Brinkman numbers on Nusselt number and results compared with simplified cases in the literature. M.M. Heyhat et al. (2013) measured experimentally pressure drop and convective heat transfer coefficient of $\mathrm{Al}_{2} \mathrm{O}_{3}$-water Nano-fluids flowing through a horizontal tube having constant wall temperature under fully developed laminar regime. To calculate the pressure drop and the convective heat transfer coefficient, all physical properties of the $\mathrm{Al}_{2} \mathrm{O}_{3}$-water Nano-fluids were measured over a temperature ranging from $20-60{ }^{\circ} \mathrm{C}$ and the nanoparticle volume fractions ranging from $0.1 \%$, $0.5 \%, 1 \%, 1.5 \%$, and $2.0 \%$. Their experimental results showed that the convective heat transfer of Nano-fluids increased by up to \%32 at concentration of 3 vol.\% compared with that of pure water and increased with the increasing the Reynolds number, particle concentrations. On the other hand, their results showed that pressure drop of the Nano-fluids were in much higher than that of base fluid. Lattice Boltzmann method (LBM) has recently been receiving considerable attention as a possible alternative to conventional computational fluid dynamics (CFD) approaches in many areas related to complex fluid flows. Pelevi et al. (2012) proposed the lattice Boltzmann model for numerical modeling of energy transport inside Nanofluids. They compared the present lattice Boltzmann simulations results with the available experimental and theoretical data for Nano-fluids.

In this study, Nano-fluid of aluminum oxide in water is investigated numerically using a Pseudospectral technique based on Chebyshev polynomial expansions. Discretization is performed by using a Pseudospectral technique based on Chebyshev polynomial expansions. The resulting nonlinear, coupled boundary value problem is solved iteratively using Chebyshev Pseudospectral method.

\section{GOVERNING EQUATIONS}

The velocity distribution of Nano-fluid flow can be obtained from the continuity and momentum equations. In order to obtain temperature distribution, energy equation is also used. Two-dimensional, nonisothermal, steady flow of an incompressible Newtonian fluid in a channel is considered. The flow is driven by a constant pressure gradient acting along the channel axis. Upper and lower walls of the channel are kept at the same constant heat flux. The Nano-fluid in the channel is taken to be Newtonian, incompressible, and laminar. The Nano-particles are also assumed to have a uniform shape and size.

The continuity, momentum balance and energy balance for a Nano-fluid can be expressed in the dimensional form as;

$$
\begin{gathered}
\frac{\partial \bar{u}}{\partial \bar{x}}+\frac{\partial \bar{v}}{\partial \bar{y}}=0 \\
-\frac{1}{\bar{\rho}_{n f}} \frac{d \bar{p}}{d \bar{x}}+\frac{\bar{\mu}_{n f}}{\bar{\rho}_{n f}}\left(\frac{\partial^{2} \bar{u}}{\partial \bar{y}^{2}}+\frac{\partial^{2} \bar{u}}{\partial \bar{x}^{2}}\right)=\bar{u} \frac{\partial \bar{u}}{\partial \bar{x}}+\bar{v} \frac{\partial \bar{u}}{\partial \bar{y}} \\
\left(\rho c_{p}\right)_{n f}\left(\frac{\partial \bar{T}}{\partial \bar{x}} \bar{u}+\bar{v} \frac{\partial \bar{T}}{\partial \bar{y}}\right)=\bar{k}_{n f}\left(\frac{\partial^{2} \bar{T}}{\partial \bar{y}^{2}}+\frac{\partial^{2} \bar{T}}{\partial \bar{x}^{2}}\right)
\end{gathered}
$$

In the equations above $\rho_{\mathrm{nf}}$ denotes the Nano fluid density, $\bar{k}_{n f}$ is the thermal conductivity, ${ }^{c_{p n f}}$ is the specific heat capacity of Nano fluid at constant pressure, $\bar{\mu}_{\mathrm{nf}}$ is the Nano fluid viscosity, $\bar{p}$ is the pressure, $\bar{T}$ denotes the local temperature, $\bar{u}$ and $\bar{v}$ are velocity components in $\bar{x}$ and $\bar{y}$ directions, respectively. 
It is more convenient for the subsequent analysis to write the governing equations in dimensionless form by introducing the following parameters:

$$
\begin{gathered}
u=\frac{\bar{u}}{\bar{u}_{0}}, \quad v=\frac{\bar{v}}{\bar{u}_{0}}, \quad x=\frac{\bar{x}}{\bar{l}}, \quad y=\frac{\bar{y}}{\bar{l}}, \\
T=\theta=\frac{\bar{T}-\bar{T}_{w}}{\bar{T}_{0}-\bar{T}_{w}}, \quad p=\frac{\bar{p}}{\bar{\rho}_{n f} \bar{u}_{0}^{2}}
\end{gathered}
$$

Using the dimensionless parameter the nondimensional form of the continuity, momentum balance and energy balance equations can be expressed in the dimensionless form as

$$
\begin{aligned}
& \frac{\partial u}{\partial x}+\frac{\partial v}{\partial y}=0, \\
& -\frac{d p}{d x}+\frac{1}{\operatorname{Re}} \frac{\rho_{f}}{\rho_{n f}} \frac{\mu_{n f}}{\mu_{f}} \frac{d^{2} u}{d y^{2}}=0, \\
& \operatorname{Re} \operatorname{Pr} u \frac{d \theta}{d x}=\frac{k_{n f}}{k_{f}} \frac{\left(\rho c_{p}\right)_{f}}{\left(\rho c_{p}\right)} \frac{d^{2} \theta}{d y^{2}}
\end{aligned}
$$

where Reynolds number (Re) and Prandtl number $(\operatorname{Pr})$ are defined as $\operatorname{Re}=\bar{\rho}_{f} \bar{U}_{0} \bar{l} / \bar{\mu}_{f}$, $\operatorname{Pr}=C_{p_{f}} \bar{\mu}_{f} / k_{f}$

To calculate the thermal conductivity $\left(k_{n f}\right)$ and viscosity ( $\mu_{\mathrm{nf}}$ ) of Nano-fluids, the Maxwell-Garnett and Brinkman's relations are considered as follows:

$$
\begin{aligned}
& \frac{k_{n f}}{k_{f}}=\frac{k_{s}+2 k_{f}-2 \phi\left(k_{f}-k_{s}\right)}{k_{s}+2 k_{f}+\phi\left(k_{f}-k_{s}\right)} \\
& \frac{\mu_{n f}}{\mu_{f}}=\frac{1}{(1-\phi)^{2.5}}
\end{aligned}
$$

The thermo physical properties (density and heat capacity) of the Nano-fluid, have been calculated from Nano-particle and the base fluid properties with the Nano-fluid volume fraction as follows [Heidary and Kermani 2010].

$$
\rho_{n f}=(1-\phi) \rho_{f}+\phi \rho_{s}
$$

$$
\left(\rho c_{p}\right)_{n f}=(1-\phi)\left(\rho c_{p}\right)_{f}+\phi\left(\rho c_{p}\right)_{s}
$$

Continuity and momentum equations are solved simultaneously with the energy equation to determine velocity and temperature distribution for different variables.

The dimensionless boundary conditions are;

$\mathrm{u}=0$ when $\mathrm{y}=0$ and $\mathrm{u}=0$ when $\mathrm{y}=1$

$\theta=0$ when $\mathrm{y}=0$ and $\theta=0$ when $\mathrm{y}=1$

Differential Equations, along with the boundary conditions, constitute the governing equations to determine the base-flow velocity and temperature profiles for the Nano-fluids. The boundary-value problem is solved numerically using a Chebyshevpseudospectral method.

The nonlinear boundary value problem described above was solved numerically by using Chebyshev-pseudospectral method. In this method, the $0 \leq \mathrm{y} \leq 1$ physical domain is first transformed to $-1 \leq \mathrm{Y}$ $\leq 1$ spectral domain.

$$
\begin{aligned}
& -\frac{d p}{d x}+t r^{2} \frac{1}{\operatorname{Re}} \frac{\rho_{f}}{\rho_{n f}} \frac{\mu_{n f}}{\mu_{f}} \frac{d^{2} u}{d Y^{2}}=0, \\
& \operatorname{RePr} u \frac{d \theta}{d x}=\operatorname{tr}^{2} \frac{k_{n f}}{k_{f}} \frac{\left(\rho c_{p}\right)_{f}}{\left(\rho c_{p}\right)_{n f}} \frac{d^{2} \theta}{d Y^{2}}
\end{aligned}
$$

Here $\boldsymbol{t r}$ is transfer coefficient and it's value is 2.0. As a second step, the velocity $u$ and temperature $\theta$ are expanded in a series of Chebyshev polynomials.

$$
\begin{aligned}
& u(Y)=\sum_{n=0}^{N} a_{n} T_{n}(Y) \\
& \theta(Y)=\sum_{n=0}^{N} b_{n} T_{n}(Y)
\end{aligned}
$$

where $a_{n}$ and $b_{n}$ are the expansion coefficients and $\mathrm{T}_{\mathrm{n}}(\mathrm{Y})$ is the Chebyshev polynomial of the first kind defined as

$$
T_{n}(\cos \theta)=\cos (n \theta) \quad \text { and } \mathrm{T}_{\mathrm{n}}(\mathrm{Y})=\cos (\mathrm{n} \operatorname{arcos} \mathrm{Y})
$$

then, 


$$
\begin{aligned}
& \frac{d u}{d Y}=\sum_{n=0}^{N} \frac{2}{c_{n}} \sum_{\substack{p=n+1 \\
p+\text { nodd }}}^{N} p a_{p} T_{n}(Y), \\
& \frac{d \theta}{d Y}=\sum_{n=0}^{N} \frac{2}{c_{n}} \sum_{\substack{p=n+1 \\
p+\text { nodd }}}^{N} p b_{p} T_{n}(Y)
\end{aligned}
$$

and second derivatives,

$$
\begin{aligned}
& \frac{d^{2} u}{d Y^{2}}=\sum_{n=0}^{N} \frac{1}{c_{n}} \sum_{\substack{p=n+2 \\
p+n \text { even }}}^{N} p\left(p^{2}-n^{2}\right) a_{p} T_{n}(Y) \\
& \frac{d^{2} \theta}{d Y^{2}}=\sum_{n=0}^{N} \frac{1}{c_{n}} \sum_{\substack{p=n+2 \\
p+n e v e n}}^{N} p\left(p^{2}-n^{2}\right) b_{p} T_{n}(Y)
\end{aligned}
$$

where $c_{0}=2$ and $c_{n}=1$ for $n \geq 1$.

The velocity and temperature governing equations become;

$$
-\frac{d p}{d x}+t^{2} \frac{1}{\operatorname{Re}} \frac{\rho_{f}}{\rho_{n f}} \frac{1}{(1-\phi)^{2.5}} \frac{d^{2} u}{d Y^{2}}=0
$$

$$
\begin{aligned}
& \operatorname{Re} \operatorname{Pr} u \frac{d \theta}{d x}=\operatorname{tr}^{2}\left(\frac{k_{s}+2 k_{f}-2 \phi\left(k_{f}-k_{s}\right)}{k_{s}+2 k_{f}+\phi\left(k_{f}-k_{s}\right)}\right) \\
& \frac{\left(\rho c_{p}\right)_{f}}{\left(\rho c_{p}\right)_{n f}} \frac{d^{2} \theta}{d Y^{2}}
\end{aligned}
$$

and the equations are expanded into Chebyshev polynomials

$$
\begin{aligned}
& \frac{d p}{d x}=\operatorname{tr}^{2} \frac{1}{\operatorname{Re}} \frac{\rho_{f}}{\rho_{n f}} \frac{1}{(1-2.5)^{\phi}} \\
& \sum_{n=0}^{N} \frac{1}{c_{n}} \sum_{\substack{p=n+2 \\
p+n \text { even }}}^{N} p\left(p^{2}-n^{2}\right) a_{p} T_{n}(Y)
\end{aligned}
$$

$$
\begin{aligned}
& \operatorname{Re} \operatorname{Pr} u \frac{d \theta}{d x}= \\
& \operatorname{tr}^{2}\left(\frac{k_{s}+2 k_{f}-2 \phi\left(k_{f}-k_{s}\right)}{k_{s}+2 k_{f}+\phi\left(k_{f}-k_{s}\right)}\right) \frac{\left(\rho c_{p}\right)_{f}}{\left(\rho c_{p}\right)_{n f}} \\
& \sum_{n=0}^{N} \frac{1}{c_{n}} \sum_{\substack{p=n+2 \\
p+\text { neven }}}^{N} p\left(p^{2}-n^{2}\right) b_{p} T_{n}(Y)
\end{aligned}
$$

On the last step a proper choice of collocation points has to be made to solve $2 \mathrm{~N}+2$ unknowns, $\mathrm{N}+1$ from $\mathrm{a}_{\mathrm{n}}$ and $\mathrm{N}+1$ from $\mathrm{b}_{\mathrm{n}}$. For this case

$$
Y_{j}=\cos \frac{\pi j}{N-2}, \quad \mathrm{j}=0,1,2, \ldots \ldots . \mathrm{N}-2
$$

is choosen. The Pseudospectral method requires that momentum and energy equations can be satisfied exactly at the collocation points above. These results in $2 \mathrm{~N}-2$ equations with the addition of four boundary conditions $(2 \mathrm{~N}+2)$ equations are obtained. Since the momentum and energy balance equations are coupled, they are solved iteratively using a nonlinear equation solver from IMSL subroutine software.

\section{RESULTS AND DISCUSSIONS}

A Nano-fluid flow for a non-isothermal channel flow under the effect of a constant pressure gradient acting along the channel axis is investigated numerically. There are various parameters here whose effects on the flow behavior must be investigated. They are dimensionless pressure gradient $(\mathrm{dp} / \mathrm{dx}=-\mathrm{G})$ that denotes the degree of fluid driving force; volume concentration, dimensionless constant temperature gradient in axial direction ( $\mathrm{d} \theta / \mathrm{dx})$, Reynolds and Prandtl numbers. During this study temperature gradient in axial direction and Prandtl number are kept as constant values 1.0 and 7.02 respectively. The thermo-physical properties of water and $\mathrm{Al}_{2} \mathrm{O}_{3}$ in the present study are the ones used by Manca et al.[2012].

The viscosity and thermal conductivity of nano-fluids are a function of volume concentration. The higher volume concentration $(\phi)$, the more viscous fluid becomes with higher thermal conductivity. To investigate temperature profile as a function of volume concentration, Figure 1(b) is plotted as for $\theta$ vs y. In this figure, it is clear that as the $\phi$ increases, the absolute value of temperature does, too. Due to decrease of the velocity causes increase of the amount of heating from the constant heat flux for the more viscous nano-fluids. Increasing volume concentration also causes increasing thermal conductivity of Nano-fluids as well as absolute value of temperature. 
The effect of volume concentration on velocity and shear stress distribution Figure1 (a) and (c) are plotted. Figure a and c show that because of higher viscosity of nano-fluid, velocity profile decreases with increasing volume concentration with the constant values of $d p / d x-0.5, \operatorname{Re}=20, \operatorname{Pr}=7.02$ and $d \theta / d x=1.0$. In contrast to velocity profile, shear stress increases as increasing of volume concentration because of increasing fluid viscosity.

Pressure gradient is one of the parameters affecting the velocity, temperature and shear stress distributions. In order to see the effect of the pressure gradient $d p / d x$ on velocity, temperature and shear stress distribution Figure 2 (a), (b) and (c) are illustrated for the values of $d p / d x=-0.5,-1.0,-2.0$. An increase in $d p / d x$ results in an increase in velocity profile and this causes directly decreasing absolute value of temperature. This can also lead to wall shear stress increasing.

Reynolds number is the other parameter also affecting the velocity temperature and shear stress distributions. The effect of Re Number has same effect as pressure gradient. Constant parameters are $d p / d x=-0.5$ and $\phi=0.05$.The effect of Re number is illustrated on the behavior of the velocity (Figure a), temperature (Figure b) and shear stress (Figure c) profiles. (a)

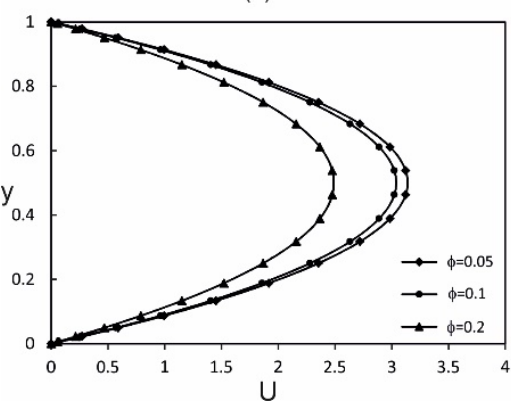

(b)

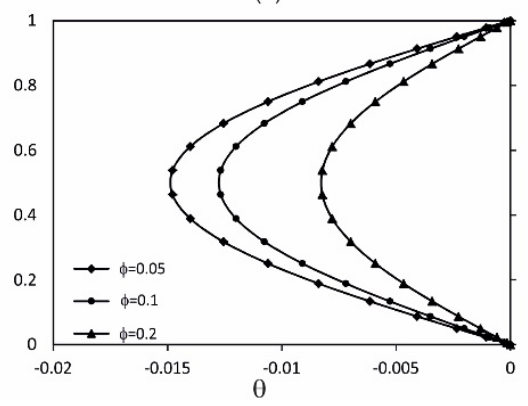

(c)

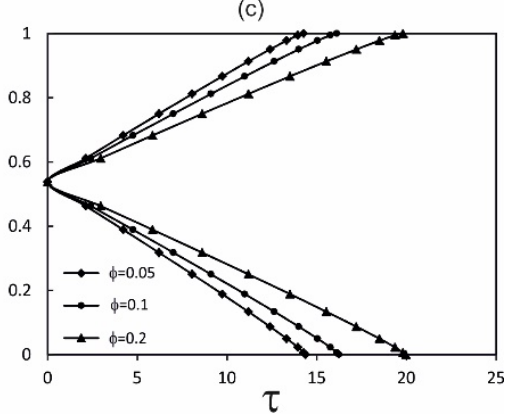

Figure 1. Plots of the velocity, temperature and shear stress for different values of volume concentration

(a)

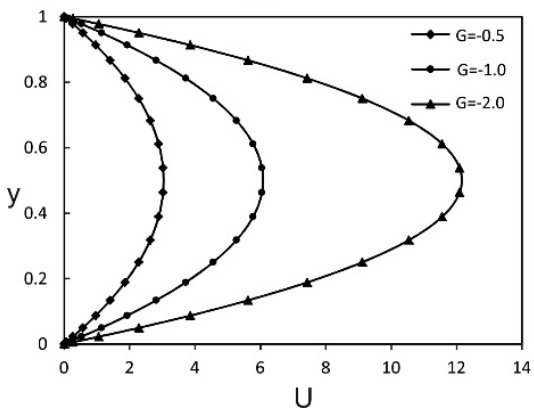

(b)

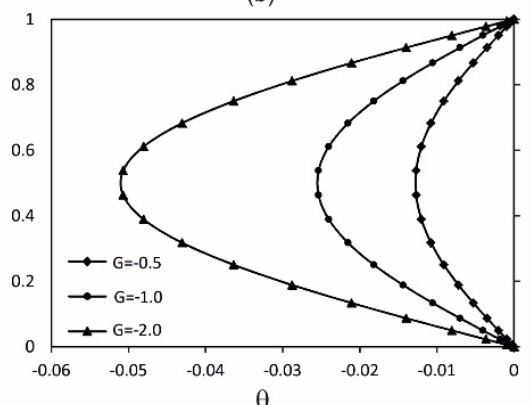

(c)

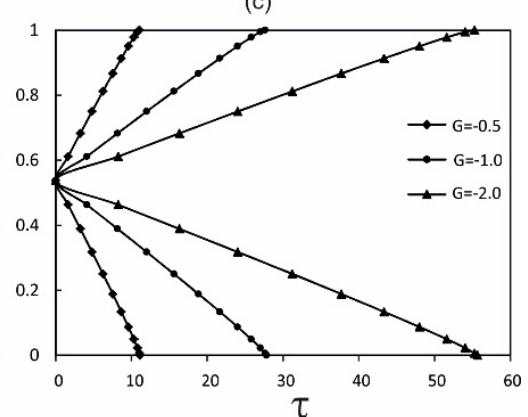

Figure 2. Plots of the velocity, temperature and shear stress for different values of pressure gradients.

(a)

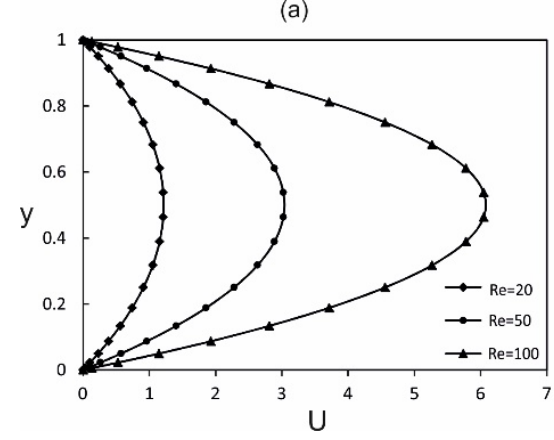

(b)

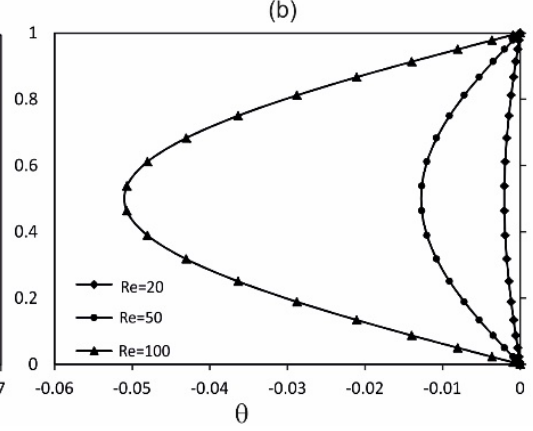

(c)

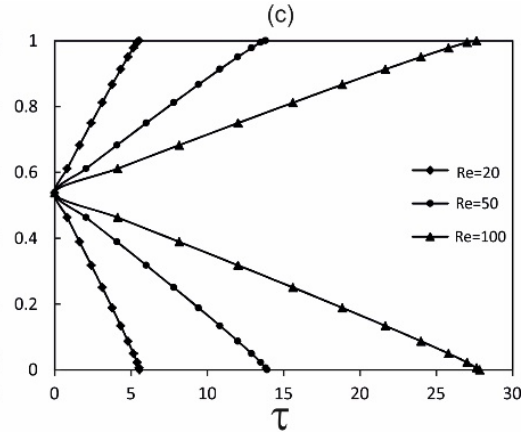

Figure 3. Plots of the velocity, temperature and shear stress for different values of Reynolds Numbers. 


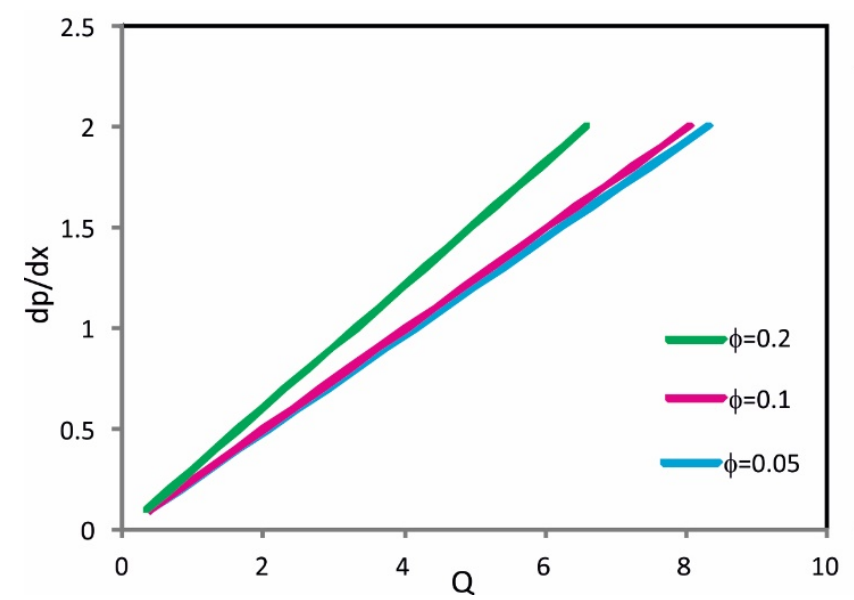

\begin{tabular}{|c|c|c|c|}
\cline { 2 - 4 } \multicolumn{1}{c|}{} & \multicolumn{3}{c|}{$\mathrm{dp} / \mathrm{dx}=-\mathrm{G}$} \\
\hline $\mathrm{Q}$ & $\phi=0.2$ & $\phi=0.1$ & $\phi=0.05$ \\
\hline 1 & 0.30 & 0.25 & 0.24 \\
\hline 2 & 0.60 & 0.50 & 0.48 \\
\hline 3 & 0.91 & 0.74 & 0.72 \\
\hline 4 & 1.21 & 0.99 & 0.96 \\
\hline 5 & 1.51 & 1.24 & 1.20 \\
\hline 6 & 1.81 & 1.49 & 1.44 \\
\hline 8 & 2.42 & 1.98 & 1.92 \\
\hline
\end{tabular}

Figure 4. Pressure gradient versus volumetric flow rate for different values of volume concentration.

\section{CONCLUSION}

In this paper, a numerical study is performed to investigate the Nano-Fluid (Al2O3) flow in Plane Poiseuille flow with constant heat flux at the wall for Newtonian, incompressible fluid. The effects of volume concentration, Re Number and Pressure gradient on flow are discussed. Key points are summarized as follows:

1. It is predicted that the fluid velocity decreases with increasing volume concentration. The higher volume concentration is, the more viscous fluid becomes with higher thermal conductivity.

2. It is noticed that an increase of volume concentration causes increasing shear stress

3. It is observed that an increase in pressure gradient results in an increase in velocity profile and this causes directly decreasing absolute value of temperature. This can also lead to wall shear stress increasing.

4. It is noticed that the effect of Re Number has the same effect as pressure gradient.

5. It is shown that an increase of volume concentration causes increasing pressure gradient for the same volumetric flow rate.

\section{ACKNOWLEDGEMENTS}

The research was supported by the Osmaniye Korkut Ata University (OKUBAP2014-PT3-037) The authors appreciate for the comments by anonymous reviewers.

\section{REFERENCES}

[1]. Maxwell, J.C. (1904). A Treatise on Electricity and Magnetism, second ed. Oxford University Press, Cambridge, pp. 435-441.

[2]. Jeffrey, D.J. (1973). "Conduction through a random suspension of spheres”, Proc. R. Soc. Lond., Series A 335, pp. 355-367.

[3]. Batchelor, G.K. (1977). "The effect of Brownian motion on the bulk stress in a suspension of spherical particles”, J. Fluid Mech., 83 (Pt.1), pp. 97-117.

[4]. Gupte, S.K., Advani, S.G., Huq, P. (1995). "Role of micro-convection due to non-affine motion of particles in a mono-disperse suspension”, Int. J. Heat Mass Transfer, 38 (16), pp. 2945-2958.

[5]. Boothroyd, R.G., Haque, H. (1970). "Fully developed heat transfer to a gaseous suspension of particles flowing turbulently in duct of different size”, J. Mech. Eng. Sci., 12 (3), pp. 191-200.

[6]. Sohn, C.W., Chen, M.M., (1981). "Microconvective thermal conductivity in disperse two-phase mixtures as observed in a low velocity Couette flow experiment”, J. Heat Transfer, 103, pp. 45-51.

[7]. Kurosaki, Y., Murasaki, T. (1986). "Study on heat transfer mechanism of a gas-solid suspension impinging jet (effect of particle size and thermal properties)", Proceedings of the 8th International Heat Transfer Conference, vol. 5, pp. 2587-2592.

[8]. Ahuja, A.S. (1982). "Thermal design of a heat exchanger employing laminar flow of particle suspensions”, Int. J. Heat Mass Transfer, 25 (5), pp. 725-728.

[9]. Masuda, H., Ebata, A., Teramae, K. Hishinuma, N. (1993). "Alteration of thermal conductivity and viscosity of liquid by dispersing ultrafine particles (dispersion of c- 
$\mathrm{Al2O} 3, \mathrm{SiO} 2$ and $\mathrm{TiO} 2$ ultra-fine particles)", Netsu Bussei, 4 (4), pp. 227-233.

[10]. Choi, S.U.-S. (1995). "Enhancing thermal conductivity of fluids with nanoparticles." ASME Publications FED-vol. 231/MD-vol. 66, pp. 99-105.

[11]. Lee, S., Choi, S.U.-S., Li, S., Eastman, J.A. (1999). "Measuring thermal conductivity of fluids containing oxide nanoparticles". J. Heat Transfer, 121, pp. 280-289.

[12]. Yu, W., France, D.M., Choi, S.U.S., Routbort, J.L. (2007). "Review and Assessment of Nanofluid Technology for Transportation and Other Applications.” ANL/ESD/07-9, Argonne National Laboratory, Argonne, IL.

[13]. Wang, X., Xu, X., Choi, S.U.S., (1999). "Thermal conductivity of nanoparticle-fluid mixture”, J. Thermophys. Heat Transfer, 13, pp. 474-480.

[14]. Xie, H., Wang, J., Xi, T., Liu, Y. (2002a). "Thermal conductivity of suspensions containing nanosized $\mathrm{SiC}$ particles”, Int. J. Thermophys., 23, pp. 571-580.

[15]. Xie, H., Wang, J., Xi, T., Ai, F. (2002b). "Thermal conductivity enhancement of suspensions containing nanosized alumina particles”, J. Appl. Phys., 91, pp. 4568-4572.

[16]. Xie, H., Wang, J., Xi, T., Liu, Y., Ai, F. (2002). "Dependence of the thermal conductivity of nanoparticles-fluid mixture on the base fluid”, J. Mater. Sci. Lett., 21, pp. 1469-1471.

[17]. Das, S.K., Putra, N., Thiesen, P., Roetzel, W. (2003). "Temperature dependence of thermal conductivity enhancement of nanofluids", Trans. ASME, J. Heat Transfer, 125, pp. 567574.

[18]. Das, S.K., Putra, N., Roetzel, W. (2003). "Pool boiling of nano-fluids on horizontal narrow tubes”, Int. J. Multiphase Flow, 29, pp. 1237-1247.

[19]. Maiga, S.E.B., Palm, S.J., Nguyen, C.T., Roy, G., Galanis, N. (2005). "Heat transfer enhancement by using nanofluids in forced convection flows", Int. J. Heat and Fluid Flow, 26, pp. 530-546.

[20]. Utomo A.T., Poth, H., Robbins, P. T., Pacek, A.W. (2012). "Experimental and theoretical studies of thermal conductivity, viscosity and heat transfer coefficient of titania and alumina nanofluids", International Journal of Heat and Mass Transfer, 55, pp. 7772-7781.

[21]. Shojaeian, M., Kosar, A. (2014). "Convective heat transfer and entropy generation analysis on Newtonian and non-Newtonian fluid flows between parallel-plates under slip boundary conditions”, International Journal of Heat and Mass Transfer, 70, pp. 664-673.
[22]. Mohammeda, H.A., Al-aswadi, A.A., Shuaib, N.H., Saidur, R. (2011). "Convective heat transfer and fluid flow study over a step using nanofluids: A review", Renewable and Sustainable Energy Reviews, 15, pp. 29212939.

[23]. "Hatami, M., Ganji, D.D., (2013). Heat transfer and flow analysis for SA-TiO2 non Newtonian nanofluid passing through the porous media between two coaxial cylinders", Journal of Molecular Liquids, 188, pp. 155161.

[24]. Bianco,V., Manca,, O., Nardini, S. (2011). "Numerical investigation on nanofluids turbulent convection heat transfer inside a circular tube”, International Journal of Thermal Sciences, 50, pp. 341-349.

[25]. Tso, C.P., Sheela-Francisca, J., Mun Hung, Y. (2010). "Viscous dissipation effects of powerlaw fluid flow within parallel plates with constant heat fluxes", J. Non-Newtonian Fluid Mech., 165, pp. 625-630.

[26]. Lotfi, R., Saboohi, Y., Rashidi, A.M. (2010). "Numerical study of forced convective heat transfer of Nanofluids: Comparison of different approaches”, International Communications in Heat and Mass Transfer, 37, pp. 74-78.

[27]. Duangthongsuk, W., Wongwises, S., (2009). "Measurement of temperature-dependent thermal conductivity and viscosity of $\mathrm{TiO} 2$ water nanofluids”, Experimental Thermal and Fluid Science, 33, pp. 706-714

[28]. Heidary,H., Kermani, M.J., (2010).“Effect of nano-particles on forced convection in sinusoidal-wall channel”, International Communications in Heat and Mass Transfer, 37, pp. 1520-1527.

[29]. Mohammed , H.A., Bhaskaran , G., Shuaib , N.H., Abu-Mulaweh, H.I. (2011). "Influence of nanofluids on parallel flow square microchannel heat exchanger performance", ,International Communications in Heat and Mass Transfer, 38, pp. 1-9.

[30]. Mahbubul, I.M., Saidur, R., Amalina, M.A. (2012). "Latest developments on the viscosity of nanofluids”, International Journal of Heat and Mass Transfer, 55, pp., 874-885.

[31]. Sun, W., Kakac, S., Yazicioglu, A.G. (2007). "A numerical study of single-phase convective heat transfer in microtubes for slip flow", International Journal of Thermal Sciences, 46, pp. 1084-1094.

[32]. Heyhat, M.M., Kowsary, F., Rashidi , A.M., Momenpour, M.H., Amrollahi, A. (2013). "Experimental investigation of laminar convective heat transfer and pressure drop of water-based $\mathrm{Al}_{2} \mathrm{O}_{3}$ nanofluids in fully developed flow regime”, Experimental Thermal and Fluid Science, 44, pp. 483-489. 
[33]. Pelevi, N., Van der Meer, Th.H., (2012). "Numerical investigation of the effective thermal conductivity of nano-fluids using the lattice Boltzmann model”, International Journal of Thermal Sciences, 62, pp. 154-159.

[34]. Manca, O., Nardini, S., Ricci, D. (2012). “A numerical study of nanofluid forced convection in ribbed channels”, Appl Therm Eng, 37, pp. 280-292. 